International Journal of Child, Youth and Family Studies (2014) 5(3): 423-446

\title{
USING MIXED METHODS TO EXPLORE RESILIENCE, SOCIAL CONNECTEDNESS, AND RE-SUSPENSION AMONG YOUTH IN A COMMUNITY- BASED ALTERNATIVE-TO-SUSPENSION PROGRAM
}

\author{
Dawn X. Henderson and Jamila Greene
}

\begin{abstract}
The study employed an explanatory sequential mixed methods design to examine resilience, social connectedness, and re-suspension rates among youth in a community-based alternative-to-suspension program. Quantitative data were collected from a sample of 102 youth participants using a baseline and post measure of resilience and social connectedness. Additional suspension data were gathered three months after participation in the program. Qualitative data were collected from a nested sample of 15 youth who participated in interviews at the middle and high school levels. Findings demonstrate a significant program effect in resilience and social connectedness; however, inconclusive results were associated with re-suspension. Quantitative and qualitative converged around the valuable role the program played in promoting youth efficacy and positive connections with adults and peers. Implications for understanding the role community-based organizations (CBOs) play in the lives of suspended youth are discussed.
\end{abstract}

Keywords: resilience, social connectedness, community-based organizations, alternatives to suspension

Acknowledgement: Funding for this project was supported by the Society for Community Research and Action (SCRA, Division 27 of the American Psychological Association).

Dawn X. Henderson, Ph.D. (the lead and corresponding author) is an Assistant Professor in the Department of Psychological Sciences at Winston-Salem State University, 203 Coltrane Hall, 601 S. Martin Luther King Jr. Drive, Winston-Salem, North Carolina, U.S.A. 27110. Telephone: (336) 750-2627, Fax: (336) 750-8650. E-mail: hendersondx@wssu.edu

Jamila Green is a graduate student in the Department of Psychology at the University of Massachusetts-Lowell, Lowell, Massachusetts, U.S.A. 01854.

E-mail: Jaymillz42088@gmail.com 
International Journal of Child, Youth and Family Studies (2014) 5(3): 423-446

In 2006 more than 3 million youth were suspended from public schools in the United States (National Center for Education Statistics, 2013) and, unfortunately, this translates into one in every 10 youth in public school being sent home. Youth who consistently receive out-ofschool suspension (OSS) are more likely to develop negative psychosocial and academic outcomes that include further truancy, diminished self-esteem, grade retention, dropping out, and involvement in the criminal justice system (Cameron, 2006; Carpenter \& Ramirez, 2007; Hatt, 2011; Hemphill, Heerde, Herrenkohl, Toumbourou, \& Catalano, 2006; Krezmien, Leone, \& Achilles, 2006). While OSS provides a clear consequence for youth who do not adhere to school policies, it disengages youth from the school context and can diminish a youth's ability to maintain bonds found in school with teachers and peers (Henry \& Huizinga, 2007). Moreover, diminishing school bonds may lead to further engagement in truant and anti-social behavior and, for some youth, academic failure (Gregory, Skiba, \& Noguera, 2010). Given these deleterious outcomes, there has been an increasing call to provide alternatives to OSS (Dupper, Theriot, \& Craun, 2009).

To date, the majority of alternative-to-suspension models are school-based (e.g., inschool suspension) or require students to attend alternative placement in schools designed to meet the unique needs of youth who may exhibit behavior challenges (Dugger \& Dugger, 1998; Eichas et al. 2010; Nichols \& Steffy, 1999). Although models may vary, similarities exist across these programs in their emphases on providing behavior management strategies (e.g., anger management and conflict resolution) and academic instruction (Dupper et al., 2009; Tobin \& Sprague, 2000). Albeit an importance context to youth, what happens when youth are not provided with these alternatives? For many youth, they are in transition between home and school and need to access other resources in order to prevent engagement in negative behavior. Other resources, such as community-based organizations (e.g., YMCA) can serve as an alternative to suspension by providing youth with the opportunity to be re-engaged in a supervised environment and continue to receive academic reinforcement. However, to the authors' knowledge, very little research has examined the role of community-based organizations in providing such alternatives.

Community-based organizations (CBOs) play an important role in facilitating and delivering prevention and intervention programs for youth (Boyle, 2002; Christensen, Pallister, Smale, Hickie, \& Calear, 2010; Hansen et al., 2013). Consequently, CBOs serve as community assets in the development of youth and, in some cases, prevent youth from engaging in such risky behaviors as substance use, unprotected sex, and violence (Mozaffarian et al., 2010; Skybo \& Polivka, 2007; Whiteley et al., 2007; Yampolskaya, Brown, \& Vargo, 2004). In addition, evidence consistently cites the important role CBOs play in promoting positive youth development; this is especially true among youth in low-income neighborhoods (Boyle, 2002; Quane \& Rankin, 2006; Wong, 2010). These organizations often serve as extensions to and partners for the youth's family and school by reinforcing community bonds and sustaining a network of positive adults youth can access (Edwards, Mumford, \& Serra-Roldan, 2007; St. Pierre, Mark, Kaltreider, \& Campbell, 2001; Tebes et al., 2007).

\section{The Role of CBOs in Resilience}

CBOs can be characterized as a promotive factor in the resilience model proposed by Fergus and Zimmerman (2005). More specifically, CBOs serve as an external resource for youth 
International Journal of Child, Youth and Family Studies (2014) 5(3): 423-446

to access by supporting positive connections with adults and facilitating youth competence (Bowers et al. 2010; Laser \& Leibowitz, 2009; Lerner, Fisher, \& Weinberg, 2000). Youth who have strong social connections with adults across their neighborhood and family are less likely to engage in risky behavior and substance use (Karcher \& Finn, 2005). These connections are central to interventions that seek to promote resilient functioning among youth (Karcher \& Sass, 2010).

When youth have a sense of connectedness to their social ecology it fosters active engagement in their community and optimal trajectories. Thus CBOs serve as an essential component to a youth's socio-ecology and play a vital role in providing social support and promoting asset-building (Cicchetti, 2003). Moreover, CBOs are relevant social institutions that provide meaningful resources to support youth well-being (Ungar et al., 2008). As a community resource, CBOs can further counter the negative effects of suspension and support youth's successful transition back into the school context. Unfortunately, very little is known about how CBOs promote resilience and serve as alternatives to OSS. The limited evidence does suggest that alternative to suspension models in CBOs support engagement in pro-social behavior and reduce re-suspension rates among youth (Bruenlin et al., 2004; Dupper, 1998; Weissman et al., 2005).

\section{Purpose of the Study}

The present study aims to understand the role of a community-based alternative-tosuspension program in increasing resilience, social connectedness, and reducing re-suspension rates among youth. More specifically, quantitative data were collected using a baseline and post intervention measure of resilience (Ungar et al., 2007; Ungar et al., 2008) and social connectedness (Lee, Draper, \& Lee, 2001) and suspension data. Qualitative data were collected using an open-ended interview from a nested sample of youth participants. To address the aims of the study, the following research questions were proposed: (a) Is there a program effect from baseline to post intervention in resilience and social connectedness among youth? (b) Are resilience and social connectedness significant predictors of youth not being re-suspended three months after their involvement in the program? (c) How do youth describe their experience in the program and its impact on their lives?

\section{Methods}

To address the research questions outlined above, the authors used an explanatory sequential mixed methods design (Creswell \& Plano Clark, 2011). The explanatory sequential mixed methods design encompasses the collection and analysis of quantitative data followed by qualitative data. In this study, quantitative data were collected on a purposive sample of 102 youth participants in the alternative-to-suspension program to examine program effects in resilience and social connectedness and rates of re-suspension. Qualitative data were collected using interviews with 15 youth participants nested in the larger sample. It was anticipated interviews would explore youth perceptions of their experience and provide a richer analysis of dynamic processes within the program. Thus the explanatory mixed methods design will use qualitative findings to explain a hypothesized increase in resilience and social connectedness through emergent youth experiences (Onwuegbuzie \& Leech, 2006). The integration of quantitative and qualitative findings will be highlighted in the discussion section (see Figure 1). 
International Journal of Child, Youth and Family Studies (2014) 5(3): 423-446

Figure 1. Model of sequential explanatory mixed methods design

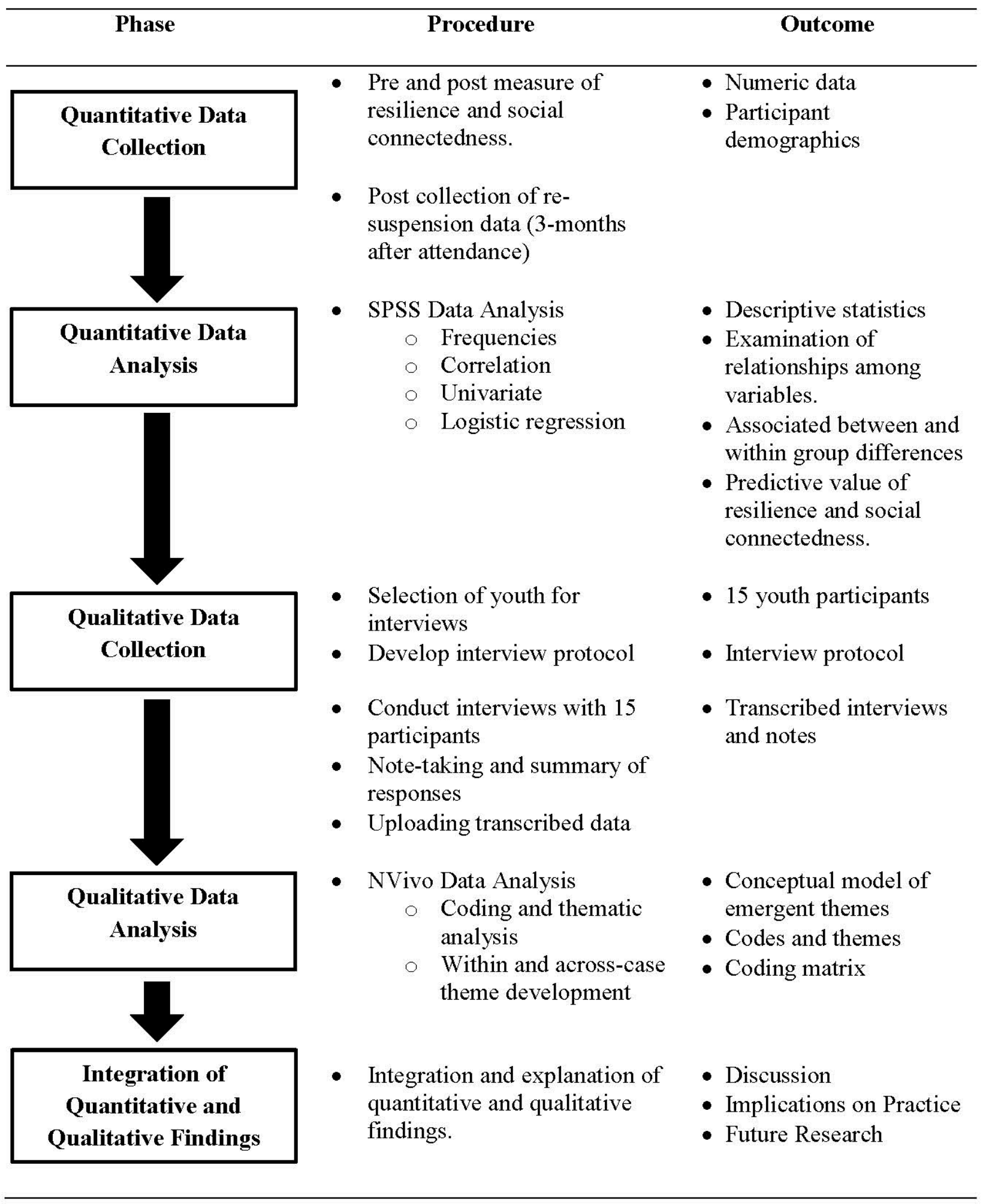


International Journal of Child, Youth and Family Studies (2014) 5(3): 423-446

\section{Participants}

A purposive sample of youth participants was recruited from the alternative-tosuspension program during the 2011-2012 academic term. A total of 162 youth participated in the program; however, 102 youth completed consent forms and served as the sampling frame for individual and group interviews. Suspended youth were referred to the program by two local school districts or required to participate through court order. The amount of time spent in the program is determined at the discretion of the referring agents (principal or assistant principal) and by the severity of offense. For example, skipping school resulted in 3 days of suspension whereas substance abuse resulted in 10 days. Youth, on average, spent 4 days in the program.

All procedures of the study were approved by the Institutional Review Board and school districts' Office of Assessment and Research. Data on youth offenses and household income were gathered from self-report measures from the program's database. The demographics of the sample are provided in Table 1 . About $50 \%$ of the youth were suspended for violent-related behaviors (e.g., fighting, bullying, and sexual harassment) and 50\% for non-violent related behaviors (e.g., disrespect, truancy, and substance use). The mean age of the sample was 15 years, of whom 61\% were between 15 and 19 and 39\% were between 11 and 14; 66\% were male and 34\% female; $63 \%$ had an annual household income less than $\$ 25,000$. The ethnic composition of the youth was 66\% minority (35\% African-American, 12\% Hispanic, 19\% multiethnic or other) and 34\% European-American.

The larger sample served as the sampling frame to recruit youth for individual and group interviews. The combination of individual and group interviews would provide insight into individual and convergent meaning (Lambert \& Loiselle, 2008; Vaughn, Schumm, \& Sinagub, 1996) of youth experiences in the program. To recruit participants for the interviews, a question was placed on the consent form asking individuals if they would like to participate in an interview. Sixty-four youth were identified and organized by demographics (e.g., gender, ethnicity, and household income) to ensure youth reflected the demographics of the larger sample. The youth were contacted to further solicit their interest and schedule interviews. A total of 15 youth participated in interviews, three homogeneous group interviews (based on gender and grade level) and three individual interviews. The description of the interview participants are outlined in Table 2. Group interviews ranged from three to five youth participants and all interviews were conducted in selected middle or high schools and lasted between 45 and 90 minutes. 
International Journal of Child, Youth and Family Studies (2014) 5(3): 423-446

Table 1. Demographics of the Sample $(n=102)$

\begin{tabular}{|c|c|c|c|}
\hline & \multicolumn{2}{|l|}{ Gender } & \multirow[t]{2}{*}{ Total } \\
\hline & Male & Female & \\
\hline Number of Participants & $67(66 \%)$ & $35(34 \%)$ & $102(100 \%)$ \\
\hline \multicolumn{4}{|l|}{ Age $(n=98)$} \\
\hline Mean & 4.91 & 5.12 & 4.98 \\
\hline \multirow[t]{2}{*}{ Standard Deviation } & 1.96 & 1.92 & 1.94 \\
\hline & $N$ & $N$ & \\
\hline \multicolumn{4}{|l|}{ Ethnicity $(n=98)$} \\
\hline African-American & $18(18 \%)$ & $16(16 \%)$ & $34(35 \%)$ \\
\hline European-American & $27(27 \%)$ & $6(6 \%)$ & $33(34 \%)$ \\
\hline Hispanic & $8(8 \%)$ & $4(4 \%)$ & $12(12 \%)$ \\
\hline Other* & $12(12 \%)$ & $7(7 \%)$ & 19 (19\%) \\
\hline \multicolumn{4}{|l|}{ Family Status $(n=94)$} \\
\hline Mother and Father & $29(31 \%)$ & $8(9 \%)$ & 37 (39\%) \\
\hline Mother Only & $23(24 \%)$ & $17(18 \%)$ & $40(43 \%)$ \\
\hline Father Only & $7(7 \%)$ & $3(3 \%)$ & $10(11 \%)$ \\
\hline Other & $5(5 \%)$ & $2(2 \%)$ & $7(8 \%)$ \\
\hline \multicolumn{4}{|l|}{ Household Income $(n=84)$} \\
\hline Less than $\$ 25 \mathrm{~K}$ & $30(36 \%)$ & $23(27 \%)$ & $53(63 \%)$ \\
\hline Between $\$ 25,001$ and $\$ 50,000$ & $12(14 \%)$ & $2(2 \%)$ & $14(17 \%)$ \\
\hline Between $\$ 50,001$ and $\$ 75,000$ & $6(7 \%)$ & $2(2 \%)$ & $8(9 \%)$ \\
\hline More than $\$ 75,000$ & $3(4 \%)$ & $6(7 \%)$ & $9(11 \%)$ \\
\hline \multicolumn{4}{|l|}{ Type of Suspension $(n=95)$} \\
\hline Violent & 31 (33\%) & $17(18 \%)$ & 48 (51\%) \\
\hline Non-violent & 31 (33\%) & $16(17 \%)$ & 47 (49\%) \\
\hline
\end{tabular}

*Other included youth participants that described themselves as "Multi-ethnic" or "AsianAmerican” 
International Journal of Child, Youth and Family Studies (2014) 5(3): 423-446

Table 2. Description of Interview Youth Participants $(n=15)$

\begin{tabular}{|c|c|c|c|c|c|c|}
\hline & Group Interview 1 & Group Interview 2 & Group Interview 3 & Individual 1 & Individual 2 & Individual 3 \\
\hline n-value & 4 & 5 & 3 & $\mathrm{n} / \mathrm{a}$ & $\mathrm{n} / \mathrm{a}$ & $\mathrm{n} / \mathrm{a}$ \\
\hline Mean age & 16.8 & 12.0 & 17.7 & 12 & 13 & 17 \\
\hline Gender & Female & Female & Male & Male & Male & Male \\
\hline \multicolumn{7}{|l|}{ Ethnicity (\%) } \\
\hline African-American & $3(75 \%)$ & $1(20 \%)$ & $1(33 \%)$ & 1 & 1 & 1 \\
\hline European-American & $1(25 \%)$ & $\mathrm{n} / \mathrm{a}$ & $\mathrm{n} / \mathrm{a}$ & $\mathrm{n} / \mathrm{a}$ & $\mathrm{n} / \mathrm{a}$ & $\mathrm{n} / \mathrm{a}$ \\
\hline Hispanic & $\mathrm{n} / \mathrm{a}$ & $3(60 \%)$ & $1(33 \%)$ & $\mathrm{n} / \mathrm{a}$ & $\mathrm{n} / \mathrm{a}$ & $\mathrm{n} / \mathrm{a}$ \\
\hline Other & $\mathrm{n} / \mathrm{a}$ & $1(20 \%)$ & $1(33 \%)$ & $\mathrm{n} / \mathrm{a}$ & $\mathrm{n} / \mathrm{a}$ & $\mathrm{n} / \mathrm{a}$ \\
\hline \multicolumn{7}{|l|}{ Family Status (\%) } \\
\hline Mother \& Father & $1(25 \%)$ & $\mathrm{n} / \mathrm{a}$ & $1(33 \%)$ & $\mathrm{n} / \mathrm{a}$ & $\mathrm{n} / \mathrm{a}$ & $\mathrm{n} / \mathrm{a}$ \\
\hline Mother Only & $3(75 \%)$ & $5(100 \%)$ & $2(67 \%)$ & $\mathrm{n} / \mathrm{a}$ & 1 & 1 \\
\hline Father Only & $\mathrm{n} / \mathrm{a}$ & $\mathrm{n} / \mathrm{a}$ & $\mathrm{n} / \mathrm{a}$ & 1 & $\mathrm{n} / \mathrm{a}$ & $\mathrm{n} / \mathrm{a}$ \\
\hline Other & $\mathrm{n} / \mathrm{a}$ & $\mathrm{n} / \mathrm{a}$ & $\mathrm{n} / \mathrm{a}$ & $\mathrm{n} / \mathrm{a}$ & $\mathrm{n} / \mathrm{a}$ & $\mathrm{n} / \mathrm{a}$ \\
\hline \multicolumn{7}{|l|}{ Type of Suspension } \\
\hline Non-violent & $3(75 \%)$ & $2(40 \%)$ & $3(100 \%)$ & $\mathrm{n} / \mathrm{a}$ & 1 & $\mathrm{n} / \mathrm{a}$ \\
\hline Violent & $1(25 \%)$ & $3(60 \%)$ & $\mathrm{n} / \mathrm{a}$ & 1 & $\mathrm{n} / \mathrm{a}$ & 1 \\
\hline
\end{tabular}


International Journal of Child, Youth and Family Studies (2014) 5(3): 423-446

\section{Context of the Study}

The program was designed to provide an alternative space (outside of being home or involved in other unsupervised settings) for suspended youth and sustain their involvement in pro-social activities (e.g., conflict resolution workshops, group and recreational activities, and academic support). The program operates out of a YMCA (Young Men's Christian Association) located in the southeastern region of the United States. On average, the program annually serves 175 suspended youth from two local school districts. It is grounded in resilience research and employs a strength-based approach that focuses on youth's resources, strengths, and their capacity for change. All youth complete a tree activity on the first day of attendance. The tree activity requires youth to work with program staff to identify youth strengths (in the roots of the tree), goals (in the leaves of the tree), and challenges (lightning). Every day youth are involved in group and recreational activities and participate in workshops facilitated by community partners in conflict resolution and management, healthy relationships, and civic engagement. The program is a free alternative for suspended youth; however, all youth may not attend the program due to parental choice and transportation access to and from the program.

\section{Measures}

Demographic Questionnaire. The demographic questionnaire was attached to the baseline measures. Youth participants were required to select their ethnic group, gender, age and birthdate, and who they lived with (e.g., mother and father, mother only, father only, and other). At the post level, youth participants were required to select the amount of time spent in the program (ranged from 1 to 3 days, to 5 to 10 or more days).

Baseline and Post Measure. The baseline and post measure contained 48-items modified using the Child and Youth Resilience Measure or CYRM (Ungar et al., 2007; Ungar et al., 2008) and Social Connectedness Scale or SCS (Lee et al., 2001). The CYRM-28 is a 28-item measure used to assess youth resources (individual, relationship with parent/caregiver, and context) that may bolster resilience. The scale has been validated across cross-cultural settings and reports high levels of content validity and internal reliability (Liebenberg, Ungar, \& Van De Vijver, 2011; Ungar \& Liebenberg, 2011). Youth respond to statements using a 5-point Likert scale from ( 1 = Not at all) to (5 = A lot) that includes statements like "I have people I look up to". A composite score is calculated, where a higher score indicates more resources (individual, relationship, and context level) to promote resilience (scores range from 28 to 140). A scale reliability analysis was conducted in SPSS using responses on the baseline measure among youth participants $(n=99)$, results revealed a Cronbach’s alpha of .85 .

The SCS is a 20-item measure used to assess the subjective awareness of interpersonal closeness and belonging within a social context (Lee et al., 2001). The scale has been used amongst diverse ethnic groups and reports concurrent validity with self-esteem and community well-being (Lee, 2005). The original 20-item scale requires individuals to respond to statements using a 6-point Likert rating scale from $(1=$ strongly disagree) to $(6=$ strongly agree). For this study, the authors collapsed the middle range (mildly agree and mildly disagree) into a rating of (neither agree nor disagree). Items include statements like "I feel close to people”. A composite score is calculated, where a higher score on the measure indicates a higher perception of social connectedness (scores range from 20 to 100). A scale reliability analysis using responses from 
International Journal of Child, Youth and Family Studies (2014) 5(3): 423-446

the baseline-measure $(n=99)$ revealed a Cronbach's alpha of .84 . These results are consistent in previous test-retest analysis where $\alpha$ range from .84 to .96 (Lee, 2005). At the post level, all youth were prompted with the statement, "Please describe how you feel right now in relation to your experience in the program to the following statements".

$\boldsymbol{R e}$-Suspension. The lead author worked with youth participants' school districts to obtain re-suspension data. Using an alphanumeric student ID, the author obtained a list of suspended youth during the academic term. The list contained initial referral and suspension date and subsequent dates if student was re-suspended. For this study, re-suspension was coded as follows: "0" meant the youth was not re-suspended three months after returning to school; and " 1 " the youth was re-suspended three months after returning to school.

Interviews. A semi-structured interview protocol was developed to engage youth participants in describing their experiences in the program and its impact in their lives (deMarrais, 2004). For example, "How would you describe the effect the program has had in your life?" was used as a leading question. All sessions were conducted by the lead author and additional notes were completed by a note-taker. Each session lasted between 45 and 90 minutes.

\section{Quantitative Analysis}

\section{Data Analysis}

An $\alpha$-level of .05 was used as the criterion for all analyses. Descriptive statistics were conducted to obtain a profile of the sample and evaluate the assumption of normality. All variables had skewness and kurtosis values between -1 and +1 , which suggest the sample was within the critical value specified. Correlations were conducted to explore the relationship between youth demographics and outcome variables. This allowed the researchers to identify any significant associations that were distinct among youth (e.g., ethnicity, age, and time in the program) and guide the regression analysis. To examine main effects in post scores of resilience and social connectedness, a MANOVA was conducted using the following independent variables: gender, baseline scores on the resilience and social connectedness measure. A logistic regression analysis was employed to determine whether post scores on the resilience and social connectedness predict re-suspension.

\section{Qualitative Analysis}

All interviews were recorded via a digital recorder, transcribed and analyzed using NVivo 10 (Bazeley \& Jackson, 2013). The transcribed data underwent a series of analytical procedures. First, the lead author used findings from the quantitative data to frame qualitative analysis. More specifically, all 15 participants' scores on the resilience and social connectedness measure were extracted from the larger sample. Individual items were reviewed from each measure and used to identify specific text segments that reflect the concept. For example, the SCS has the following item: I feel close to people; thus text segments were identified and coded that explicate how this manifested among youth interviews. This deductive analytic approach allowed the research team to support predefined codes that would address a relational domain (Esterberg, 2002). Two coders independently reviewed the transcripts and assigned predefined codes to the text segments for each interview (LeCompte, 2000). The lead author reviewed similarities and differences 
International Journal of Child, Youth and Family Studies (2014) 5(3): 423-446

across each interview and explored unique relationships between group attributes (e.g., gender) and codes. A total of 20 out of 23 codes were captured across all interviews by both coders, indicating a percent agreement of .87. The codes were then used to develop themes presented in the results section (Braun \& Clarke, 2006).

\section{Results}

\section{Quantitative}

Scores on the resilience measure at baseline ranged from 71 to 127; post level scores ranged from 67 to 130 . About $43 \%$ of the youth scores decreased from baseline to post level. Scores on the social connectedness measure at baseline ranged from 44 to 97; post level scores ranged from 57 to 100 . About $23 \%$ of youth scores decreased from the baseline to post level. A new set of variables were computed to create two groups of youth: youth who decreased scores in resilience and social connectedness (coded as 1) and youth who increased scores in resilience and social connectedness (coded as 2). The author conducted an independent $t$-test to determine if there were significant differences between youth who increased versus decreased post scores. Results indicated youth who increased their scores in resilience $(M=97.72, S D=13.0)$ scored lower at baseline than youth whose scores decreased $(M=104.31, S D=13.18), t(98)=2.47, p<$ .05). This was true on the social connectedness measure; results indicated that youth who increased scores in social connectedness scored lower at baseline $(M=69.43, S D=10.67)$ than youth whose scores decreased $(M=75.23, S D=11.50), t(98)=2.29, p<.05)$. The results indicate group differences in baseline scores and were used in the multivariate analysis. In regards to overall means, scores on the post measure of resilience $(M=103.03, S D=12.87)$ were significantly higher than scores on the baseline measure $(M=100.76, S D=13.28), t(99)=-$ $2.00, p<.05, r=.20$; scores on the post measure of social connectedness $(M=79.64, S D=$ $12.00)$ were significantly higher than scores on the baseline measure $(M=70.85, S D=11.09), t$ (99) $=-6.46, p<.001, r=.55$.

The correlation matrix indicated that there were no significant associations between youth participant demographics and scores on the CYRM-28 and SCS at baseline and post level (Table 3). However, there were some interesting findings related to type of suspension and resuspension in the analysis. For example, type of suspension was significantly related to scores on the baseline measure of resilience $(r=.23, p<.05)$, suggesting that youth who entered the program with non-violent related suspensions scored higher on the resilience baseline measure. Unfortunately, this only accounted for $5 \%$ of variability on the baseline resilience measure. Resuspension was significantly related to scores on the post measure of resilience $(r=-.23, p<.05)$ but was not significantly related to scores on the post measure of social connectedness $(r=-.17$, $p=.10$ ). Loosely interpreted, these results suggest that individuals who were not re-suspended had higher scores on the resilience measure at the post level.

Since there appeared to be two groups within the scores - that is, youth who demonstrated an increase in scores from the baseline to post level and youth who demonstrated a decrease - a new dichotomous variable was explored. The variable contained two levels, $1=$ decrease and 2 = increase. Therefore, a MANCOVA was used to assess group differences in resilience and social connectedness at the post level using baseline scores on the resilience and 
social connectedness measures as covariates. Significant results are provided in Table 4 . In the resilience post measure, findings indicate significant main effects for baseline scores in resilience, $F(1,85)=157.12, p<.01, r=.79$, and score difference group, $F(1,85)=98.56, p<$ $.01, r=.46$. In the social connectedness post measure, findings indicate significant main effects for baseline scores in resilience, $F(1,85)=10.72, p<.01, r=.32$, social connectedness, $F(1$, $85)=20.70, p<.01, r=.41$, and score difference group, $F(1,85)=52.61, p<.01, r=.24$. There were no significant main effects for gender or interaction effects for the four independent variables. These results further support findings from the independent $t$-tests.

The results from the correlation suggest that no linear relationship exists among youth demographic variables and baseline and post scores of social connectedness, therefore the logistic analysis regressed re-suspension on post scores in resilience. Baseline scores on the resilience measure and score differences were entered as covariates; this would allow the researchers to examine unique contributions of post scores and determine whether each variable influenced variation. Results from the model indicate that $76 \%$ of youth were classified correctly. Unfortunately, scores on the resilience baseline measure did not significantly predict re-suspension (Wald statistic $=2.01, p=.16$, with $d f=1$ ); in block 2 the baseline measure remained non-significant and scores on the post measure of resilience was not significant (Wald statistic $=2.87, p=.09$, with $d f=1$ ). To address multicollinearity between variables, the lead author conducted diagnostics using a simple linear regression. The tolerance values were not lower than .1 and VIF value was not greater than 10, which suggest that multicollinearity did not present a major issue for our findings. 
Table 3. Correlations between Youth Participant Demographics and CYRM-28 and SCS Measures

\begin{tabular}{|c|c|c|c|c|c|c|c|c|c|c|c|c|}
\hline & $\mathrm{AGE}$ & GDR & ETHN & LVWT & PRCYRM & PSTCYRM & PRSCS & PSTSCS & INCM & TINT & TSUSP & SUSP \\
\hline AGE & 1 & & & & & & & & & & & \\
\hline GDR & .05 & 1 & & & & & & & & & & \\
\hline ETHN & .12 & .12 & 1 & & & & & & & & & \\
\hline LVWT & & .00 & .13 & 1 & & & & & & & & \\
\hline PRCYRM & .05 & .20 & .09 & -.09 & 1 & & & & & & & \\
\hline PSTCYRM & -.13 & .01 & .11 & -.07 & $.62 * *$ & 1 & & & & & & \\
\hline PRSCS & -.07 & .18 & .02 & .05 & $.32 * *$ & $.31 * *$ & 1 & & & & & \\
\hline PSTSCS & -.14 & .05 & .11 & -.02 & $.40 * *$ & $.58 * *$ & $.57 * *$ & 1 & & & & \\
\hline INCM & .09 & -.06 & -.18 & -.15 & -.10 & -.13 & -.01 & -.12 & 1 & & & \\
\hline TINT & $.22 *$ & .14 & -.08 & -.04 & -.10 & -.13 & -.01 & -.12 & .06 & 1 & & \\
\hline TSUSP & -.10 & .02 & .10 & .12 & $.22 *$ & .20 & -.07 & .07 & .01 & .01 & 1 & \\
\hline SUSP & -.05 & -.00 & .08 & .02 & -.15 & $-.23 *$ & -.12 & -.17 & .01 & .11 & -.01 & 1 \\
\hline
\end{tabular}

Note. GDR = Gender, ETHN = Ethnicity, LVWT = Leave with, CYRM = Child Youth Resilience Measure, SCS= Social

Connectedness Scale, INCM = Income, TINT = Time in Intervention, TSUSP = Type of Suspension, SUSP = Re-suspended, yes or no.

$*=p<.05, * *=p<.01$ 
International Journal of Child, Youth and Family Studies (2014) 5(3): 423-446

Table 4. Multivariate Tests for Significance $(\mathrm{p}<.05)$

\begin{tabular}{lllll}
\hline Effect & Pillai’s Trace & $F$ & $d f_{1}$ & $d f_{2}$ \\
\hline PRCYRM & .65 & 78.90 & 2 & 84 \\
PRSCS & .20 & 10.25 & 2 & 84 \\
CRYMHILO & .54 & 48.74 & 2 & 84 \\
SCSHILO & .40 & 27.47 & 2 & 84 \\
\hline
\end{tabular}

Note. PRECYRM = Baseline measure of resilience, PRSCS = Baseline measure of social connectedness, CRYMHILO = groups by increase or decrease in resilience scores, SCSHILO = groups by increase or decrease in resilience scores.

Qualitative. The qualitative findings explicate results from the quantitative phase of the study. Specifically, items from the measures were used to identify emergent themes that yield the value of youth-adult and youth-youth interactions and their role in improving youth's attitudes and self-beliefs. Three themes were developed and delineate youth experiences in the program using positive relationships with adults and peers and increased self-efficacy (Figure 2). The results are described as many (range from 10 to 15), some (range from 5 to 9), and a few (less than 5).

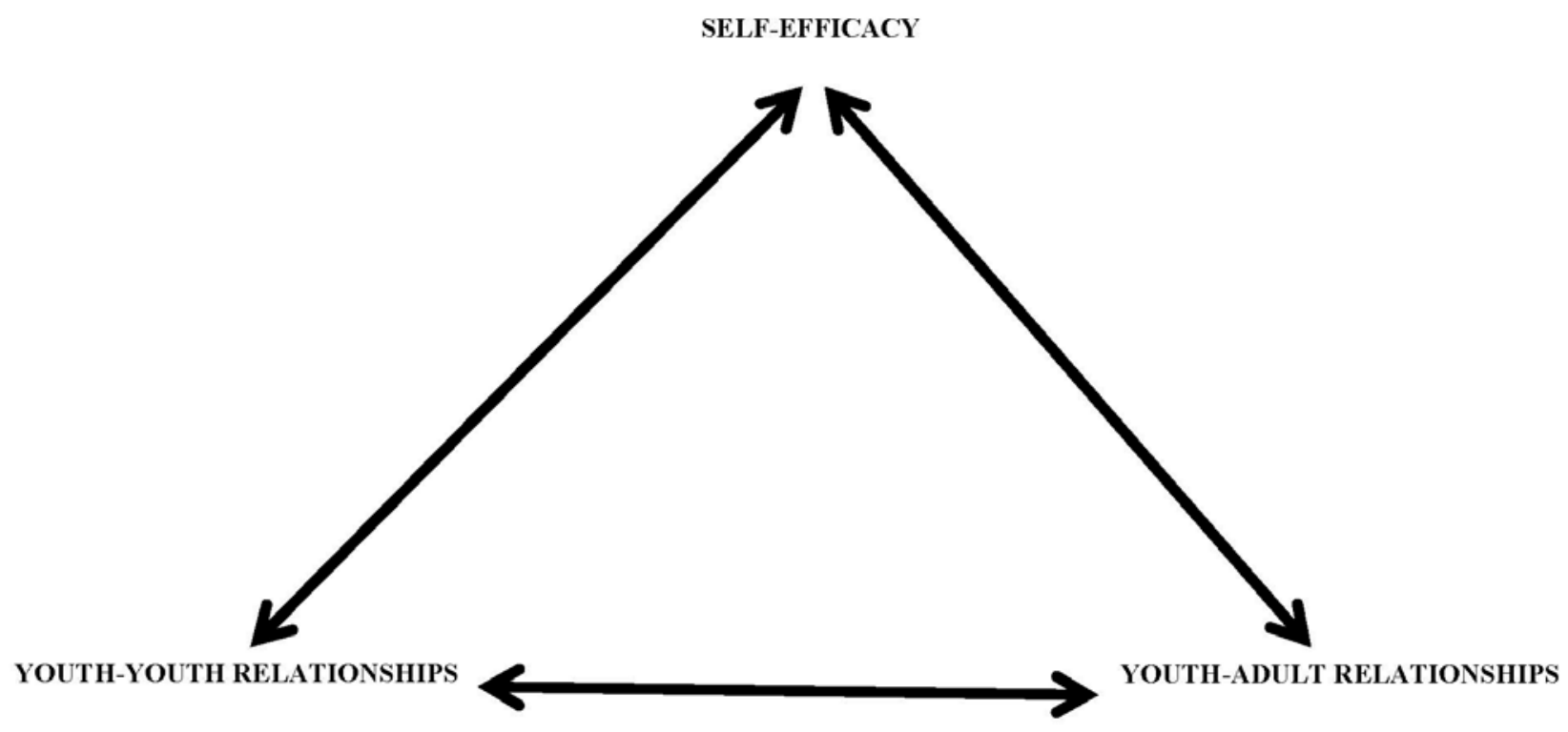

Figure 2. Conceptual model demonstrating the relationship between themes 
International Journal of Child, Youth and Family Studies (2014) 5(3): 423-446

Self-efficacy. In this study self-efficacy was conceptualized from codes such as academic achievement, improved attitudes about school, and recognition of individual strengths and demonstrates how youth felt competent and encouraged. Self-efficacy emerged from social cognitive theory and describes how personal and environmental factors interact to influence youth behaviors and ability (Bandura, 2001). In this analysis, self-efficacy characterized the bidirectional relationship between psychological and social domains observed from the interviews. Another important code under this theme was autonomy, which denotes the ability of youth to form their own choices and manage activities. Many of the youth discussed how the program provided them with opportunities to choose their academic work and recreational activity.

[I'm] thinking like [the program] is not like school...you pick your own choices of what you want to do the whole time while you're there...you get to pick what subject you want to do first and then during lunch or during activity time you can pick what you want to do there also. (GI1)

Across all interviews, youth perceived the program as a place where they increased an awareness of their abilities and strengths and how this translated into other domains of their social ecology (e.g., school, peers, and parents). This can be captured in Bandura (2005) and Pajares' (2006) assertion of self-governance among youth and its role in increasing perceptions of competence and personal agency. Additionally, many youth discussed their engagement in self-reflection through morning group activities and positive decision-making. Text segments such as "recognizing my strengths”, “changing my attitude”, and "managing anger” emerged across male and female participants.

I always got angry over some things...I always wanted to get into a fight...umm, if someone talked junk about me or if they disrespected me, I would get angry, I would go confront them and be all in their space and about to hit them but that changed. (GI2)

It affected me....it made me and my family closer....me and my dad are have a better relationship....I do better in school...I don't fight anymore. (I1)

Many of the youth discussed the value of academic support received in the program. Youth discussed how this was an important aspect of their experience and provided them with opportunities to maintain their academic work during out-of-school time. Text segments such as "made me think about work differently", "make sure you succeed”, and "having more one-onone academic time" were coded as academic support. When asked about how this experience was different from school, one participant responded:

I guess like the [staff] and like the people that work there are more like hands on with the kids and they really help you a lot, like with if you have projects to do or just classwork to do...it was like we had a few hours to do work, but I didn't really notice because I was like actually engaged. (I2)

To frame the next themes, it is important to highlight how these converge with our quantitative findings, specifically to social connectedness. Items from the social connectedness measure were used to match codes and corresponding text segments across all interviews (Table 5) and guided the discussion section. 
Youth-Youth Relationships. Youth-youth relationships emerged as an important theme across all interviews. Although youth knew they were all there by way of suspension, the program allowed them to meet new people across schools and realize similar challenges. Text segments such as "meeting new people", "maintaining friendship", and "we are all friends now" illustrate the bonds youth form with peers. Moreover, the use of group activities in morning icebreakers allowed youth to be vulnerable and share personal challenges. This social activity provided an opportunity for youth to get to know other peers and form lasting relationships.

And you get to meet like a lot of people you don't know even though if they like in different schools and everything like you get to know them. (GI2)

The program also sponsored extension activities like reunion and after-school tutoring and workshops to youth participants. It was through these experiences youth maintained relationships with each other and pursued experiences outside the context of the program. As one group of female participants indicated when discussing experiences with other students:

It helped me and her relationship...we used to fight but we are friends now. But now we are like closer than before and I trust her, she told me what was wrong 'cause she been through a lot and she tries to make sure I never go through that. (GI2)

Youth-Adult Relationships. Youth perceived the staff as being nurturing and codes such as "safe place”, "feeling valued”, and “care for" were consistent across all interviews. Participants also valued the sustained relationships with staff after leaving the program and discussed the ability to always return for support. Through their involvement in the program, youth were able to access social support and garner resources from adults through positive messages and referrals to other support services. The structured time in academic support and recreational activities were important spaces for participants to bond with adult volunteers and staff. Participants valued the academic time, one-on-one assistance, and its relation to achieving their own academic goals outside of school. For example, one youth mentioned:

[Through the program]...at least I want to stay in school and graduate. (GI1)

Additionally, the characteristics of the staff centered on being caring, supportive, and having the ability to recognize youth strengths. For some youth, interacting with adults who gave them a "clean slate" and focus on their strengths and resources were vital to their experience. One participant discussed how staff interactions allowed them to perceive the environment not punitively but rather a place to instill important skills:

[It is] not really like a punishment...I guess it is sort of like a punishment but it's not. 'Cause it's like practically teaching you life skills and all that. (I1)

Emergent processes associated with the value of social support and accessing human and organizational resources was evident in this theme. Speaking about how the staff made them feel, one participant stated: 
International Journal of Child, Youth and Family Studies (2014) 5(3): 423-446

So they made us feel like welcome and special...like I used to feel that no one actually cared about me and when I got there everybody was so kind and they told me they knew and support me and cared about me and that's when I felt like I had people that actually cared about me and wanted to do good. (GI2)

\section{Discussion}

The aims of this study were to examine the effects of a community-based alternative-tosuspension program in promoting resilience and social connectedness among youth and reducing re-suspension. Program effect in resilience and social connectedness was moderately supported. An analysis of mean differences did demonstrate that there was a significant increase in resilience and social connectedness from the baseline to post level; however, the results indicate a small effect in resilience. Examining two groups of students, those whose scores increased versus decreased, results indicate a moderate but significant main effect in post scores. The greatest gains among youth participants were demonstrated in social connectedness. Given qualitative findings, it is clear that youth began to form bonds with program staff and peers and these were extremely valuable to the youth and how they constructed meaning in the program.

The inconclusive findings from the logistic regression model would suggest that neither resilience nor social connectedness predict the likelihood of youth not being re-suspended. Although the lead author anticipated that high scores on the measures would decrease a youth's chance of re-suspension, the results did not support this claim. The lead author would like to acknowledge that this is indicative of similar findings using psychosocial constructs in predicting re-suspension rates (Dupper, 1998; Bruenlin et al., 2004). In this paper, ethnicity, gender, and other youth demographic variables were not associated with re-suspension and thus were not explored in the regression analysis.

There are a number of explanations associated with these findings; for one, youth spent a relatively short (average attendance $=4$ days) amount of time in the program. Since $50 \%$ of youth participants were suspended for non-violent related offenses (e.g., skipping school), it is possible that the lack of serious offense may not necessarily be indicative of higher suspension rates. Research does suggest that youth who have chronic behavior problems (e.g., fighting and insubordination) are more likely to be re-suspended (Raffaele Mendez, 2003). Secondly, a majority of youth in the sample was not re-suspended (75\%) and other extraneous variables may contribute to this outcome outside of program participation. 


\section{Table 5. Matrix Identification of Items from the SCS Measure, Codes, and Text Segments}

\begin{tabular}{|l|}
\hline \multicolumn{1}{c}{ SCS (Items) } \\
\hline $\begin{array}{l}\text { Item 5. I feel close to } \\
\text { people }\end{array}$ \\
\hline
\end{tabular}

\section{Item 6. I feel connected} to the world around me

Item 8 . I see people as friendly and approachable

Item 10. I feel understood by the people I know

\section{Sense of community}

Value talents and strengths

Increase social network

Engagement with peers

Improved relationships with family

Improved perceptions of adults

\section{Positive connections with} adults

Improved relationships with
family

Yeah...you can definitely go and they help you out with your problems. Like if you're willing to come out and tell them. You can always go back (GI3).

Cause it's like people that you don't know....and they make you feel special, like the [staff] male you feel special, I mean I am scared of counselors [but they], yeah they make you feel special (GI2).

I really suggest it to everybody that's going through tough times, they make you feel welcome and they actually support you...they actually make you feel welcome like you are needed in this world and they give you pictures in your head of "wow"...they make your relationships better (GI2)

At [the program] you get to change and turn your life around....they are really helpful, not like our teachers...they are right beside us helping us, lending a hand (I3)
Item 12. I am able to relate to my peers

Item 16. I am able to connect with other

people

Item 20. I feel I

participate with

individuals and a group
Get more oriented with peers and you like talk to them and more [time] is provided (GI1).

Like I really didn't know anyone once I got there but then like every morning they have this thing where you like introduce everyone that's there and I like I [really] got to know everyone there (I1).

[The program] had me change...cause I started thinking positive and I started trusting my mom and my friends here and telling everyone things like even personal things that I really didn't like telling. I trust them.... it was actually really good (GI2).

[The program] helped me with how I look at grownups too. I used to, they used to tell me advice and I would just like blow it off like I don't care. Yeah, okay whatever. Now I take it in and try and use it (GI3)

Note. GI = Group Interview, I = Interview 
International Journal of Child, Youth and Family Studies (2014) 5(3): 423-446

The convergence of quantitative and qualitative findings illustrates the important value of community-based organizations, specifically among suspended youth, a psychological sense of connectedness. Bowers et al. (2010) suggest these connections are vital to youth success and their ability to navigate adversity. The findings also demonstrate the dynamic interaction between environmental, personal, and behavioral factors outlined in self-efficacy theory (Bandura, 2001; Pajares, 2005). Convergence of qualitative and quantitative findings also alludes to youth's subjective interpretation of closeness and awareness of the interpersonal relationships that exist within the program. In many ways, these findings contribute to the literature on the importance of youth-adult connections in promoting the capacity of youth to lead thriving lives (Brennan, 2008; Hansen et al., 2013). Additionally, youth perceptions of the relationships and closeness with adults in the program may further elucidate the increase in social connectedness.

\section{Limitations}

There are some inherent limitations in this study and threats to internal validity. For one, given the relative short time spent in the alternative-to-suspension program it is possible the participants were familiar with the items on the measure and thus responses on the post measures were similar to the baseline measures. Given the relative small sample and effect size (i.e., resilience), it is possible that Type 1 error occurred; this is especially true when observed power is below .50. The magnitude of the observed effect (change as a result of program) was small in the resilience measure (.23) and only explained about $9 \%$ of the variance in the sample. Thus it is evident that there may be confounding factors explaining our results and the associated change in resilience and social connectedness. Also, it is important to note that youth scores on the resilience and social connectedness baseline measure were not indicatively low (mean = 100.76; 70.85). For example, the lowest score on the baseline measure of resilience was 71 and only about 6\% scored less than 80 . Lastly, this study did not include a comparison group to assess whether unique program effects existed for youth in the program versus those who did not attend.

Our qualitative findings are limited to the perceptions of youth who participated in interviews (12\% of the study population). Although the use of interviews is common in qualitative research, it is possible that youth may have withheld specific responses to some of the questions or simply agreed with other youth during group interviews (group conformity). In addition, this study did not expand interviews beyond the selected group of youth to reach a point of saturation (Morse, Barrett, Mayan, Olson, \& Spiers, 2002). Additionally, although the authors followed procedures to ensure youth interviews represented the demographics of the program, it is evident that some of the youth's experiences are not present in the findings. The lead author also acknowledges some gaps in conceptualizing resilience and social connectedness in this study.

Despite these limitations, findings from this study expand the significance of CBOs in promoting youth psychosocial skills and connections to their socio-ecology. As alternatives to suspension, CBOs can play an active role in keeping youth engaged in pro-social activities and promoting efficacy. CBOs are linked to the social ecology of youth and there is a need to engage in research that broadens the ways in which they support youth along the developmental 
International Journal of Child, Youth and Family Studies (2014) 5(3): 423-446

continuum. More work is needed to further expand the unique mediating role CBOs play between schools and families and how this translates in youth developmental trajectories.

\section{Conclusion}

Considering the daunting statistics associated with youth who receive out-of-school suspension (Arcia, 2006; Carpenter \& Ramirez, 2007; Hatt, 2011; Hemphill et al., 2006; Gregory et al., 2010), there exists a need to identify alternatives. More importantly, it is imperative to identify alternative settings that provide youth with environments that reinforce pro-social skills, academic support, and community engagement. CBOs have the advantage of mitigating the relationship between being suspended and disengaged youth and risks. Findings from the study reveal that there are immediate advantages for youth who participated in a community-based alternative-to-suspension program and demonstrate how CBOs, like the YMCA, continue to address a variety of youth developmental needs and serve as "safe places" for youth (Mozaffarian et al. 2010; Skybo \& Polivka, 2007; Whiteley et al., 2007; Yampolskaya, et al., 2004). 
International Journal of Child, Youth and Family Studies (2014) 5(3): 423-446

\section{References}

Arcia, E. (2006). Achievement and enrollment status of suspended students: Outcomes in a large, multicultural school district. Education and Urban Society, 38(3), 359-369. http://dx.doi.org/10.1177/0013124506286947

Bandura, A. (2001). Social cognitive theory: An agentic perspective. Annual Review Psychology, 52, 1-26. http://dx.doi.org/10.1111/1467-839x.00024

Bandura, A. (2005). Adolescent development from an agentic perspective. In T. Urdan \& F. Pajares (Eds.), Self-efficacy beliefs of adolescents (pp. 1-43). Charlotte, NC: Information Age Publishing

Bazeley, P., \& Jackson, S. (2013). Qualitative data analysis with NVivo (2nd ed.). Thousand Oaks, CA: Sage Publications

Bowers, E. P., Li, Y., Kiely, M. K., Brittian, A., Lerner, J. V., \& Lerner, R. M. (2010). The 5 Cs model of positive youth development: A longitudinal analysis of confirmatory factor structure. Journal of Youth \& Adolescence, 39(7), 720-735. doi: 10.1007/s10964-0109530-9

Boyle, P. (2002). Proof at last: Youth development programs do work! Education Digest, 67(6), 40-46.

Braun, V., \& Clarke, V. (2006). Using thematic analysis in psychology. Qualitative Research in Psychology, 3, 77-101. http://dx.doi.org/10.1191/1478088706qp063oa

Brennan, M. A. (2008). “Conceptualizing resiliency: An interactional perspective for community and youth development.” Special issue of Child Care in Practice Building - Resilience in Children, Families, and Communities, 14(1), 55-64.

Bruenlin, D. C., Cimmarusti, R. A., Bryant-Edwards, T. J., \& Hetherington, J. S. (2004). Conflict resolution training as an alternative to suspension for violent behavior. The Journal of Educational Research, 95(6), 349-357. http://dx.doi.org/10.1080/00220670209596609

Cameron, M. (2006). Managing school discipline and implications for school social workers: A review of the literature. Children and Schools, 28, 219-227. http://dx.doi.org/10.1093/cs/28.4.219

Carpenter, D., \& Ramirez, A. (2007). More than one gap: Dropout rate gaps between and among black, Hispanic, and white students. Journal of Advanced Academics, 19(1), 32-64.

Christensen, H., Pallister, E., Smale, S., Hickie, I. B., \& Calear, A. L. (2010). Community-based prevention programs for anxiety and depression in youth: A systematic review. Journal of Primary Prevention, 31(3), 139-170. doi: 10.1007/s10935-010-0214-8 
International Journal of Child, Youth and Family Studies (2014) 5(3): 423-446

Cicchetti, D. (2003). Foreword. In S. S. Luther (Ed.), Resilience and vulnerability: Adaptation in the context of childhood adversities (pp. xix-xxvii). Cambridge, UK: Cambridge University Press.

Creswell, J. W., \& Plano Clark, V. L. (2011). Designing and conducting mixed methods research (2nd ed.). Los Angeles: Sage Publications.

deMarrais, K. (2004). Qualitative interview studies: Learning through experience. In K. deMarrais, \& S. D. Lapan (Eds.), Foundations for research: Methods of inquiry in education and the social sciences (pp. 51-68). Mahwah, NJ: Lawrence Erlbaum.

Dugger, J. M., \& Dugger, C.W. (1998). An evaluation of a successful alternative high school. The High School Journal, 81(4), 218-228.

Dupper, D. R. (1998). An alternative to suspension for middle school youths with behavior problems: Findings from a "school survival” group. Research on Social Work Practice, 8(3), 354-366. http://dx.doi.org/10.1177/104973159800800307

Dupper, D. R., Theriot, M. T., \& Craun, S.W. (2009). Reducing out-of-school suspensions: Practice guidelines for school social workers. Children and Schools, 31(1), 6-14.

Edwards, O. W., Mumford, V. E., \& Serra-Roldan, R. (2007). A positive youth development model for youth considered at-risk. School Psychology International, 28(1), 28-45. http://dx.doi.org/10.1177/0143034307075673

Eichas, K., Albrecht, R. E., Garcia, A. J., Ritchie, R. A., Varela, A., Garcia, A., et al. (2010). Mediators of positive youth development intervention change: Promoting change in positive and problem outcomes. Child \& Youth Care Forum, 39(4), 211-237. doi: 10.1007/s10566-010-9103-9

Esterberg, K. G. (2002). Qualitative methods in social research. Boston: McGraw Hill.

Fergus, S., \& Zimmerman, M. A. (2005). Adolescent resilience: A framework for understanding healthy development in the face of risk. Annual Review of Public Health, 26, 399-419. http://dx.doi.org/10.1146/annurev.publhealth.26.021304.144357

Gregory, A., Skiba, R., \& Noguera, P. (2010). The achievement gap and the discipline gap: Two sides of the same coin. Educational Researcher, 39, 59-68. doi: 10.3102/0013189X09357621

Hansen, L. O., Tinney, B., Asomugha, C. N., Barron, J. L., Rao, M., Curry, A., et al. (2013). "You Get Caught Up": Youth decision-making and violence. Journal of Primary Prevention, 35, 21-31. doi: 10.1007/s10935-013-0328-X.

Hatt, B. (2011). Still I rise: Youth caught between the worlds of schools and prisons. Urban Review: Issue and Ideas in Public Education, 43(4), 476-490. http://dx.doi.org/10.1007/s11256-011-0185-y 
International Journal of Child, Youth and Family Studies (2014) 5(3): 423-446

Hemphill, S. A., Heerde, J. A., Herrenkohl, T. I., Toumbourou, J. W., \& Catalano, R. F. (2006). The effect of school suspensions and arrests on subsequent adolescent antisocial behavior in Australia and the United States. Journal of Adolescent Health, 39(5), 736-744. http://dx.doi.org/10.1016/j.jadohealth.2006.05.010

Henry, K. L., \& Huizinga, D. H. (2007). School-related risk and protective factors associated with truancy among urban youth placed at-risk. Journal of Primary Prevention, 28(6), 505-519. doi: 10.1007/s10935-007-0115-7

Karcher, M. J., \& Finn, L. (2005). How connectedness contributes to experimental smoking among rural youth: Developmental and ecological analyses. Journal of Primary Prevention, 26, 25-36. doi: 10.1007/s10935-004-0989-6

Karcher, M. J., \& Sass, D. (2010). A multicultural assessment of adolescent connectedness: Testing measurement invariance across gender and ethnicity. Journal of Counseling Psychology, 57(3), 274-289. doi:10.1037/a0019357

Krezmien, M. P., Leone, P. E., \& Achilles, G. E. (2006). Suspension, race, and disability: Analysis of statewide practices and reporting. Journal of Emotional and Behavioral Disorders, 14(4), 217-226. http://dx.doi.org/10.1177/10634266060140040501

Lambert, S. D., \& Loiselle, C. G. (2008). Combining individual interviews and focus groups to enhance data richness. Journal of Advanced Nursing, 62(2), 228-237. doi: 10.1111/j.1365-2648.2007.04559.x

Laser, J. A., \& Leibowitz, G. S. (2009). Promoting positive outcomes for healthy youth development: Utilizing social capital theory. Journal of Sociology \& Social Work, 36(1), 87-102.

LeCompte, M. D. (2000). Analyzing qualitative data. Theory into Practice, 39(3), 146-154.

Lee, R. M., Draper, M., \& Lee, S. (2001). Social connectedness, dysfunctional interpersonal behaviors, and psychological distress: Testing a mediator model. Journal of Counseling Psychology, 48(3), 310-318. http://dx.doi.org/10.1037//0022-0167.48.3.310

Lee, R. M. (2005). Resilience against discrimination: Ethnic identity and other-group orientation as protective factors for Korean Americans. Journal of Counseling Psychology, 52(1), 36-44. doi: 10.1037/0022-0167.52.1.36

Lerner, R. M. Fisher, C. B., \& Weinberg, R. A. (2000). Toward a science of and for the people: Promoting civil society through the application of developmental science. Child Development, 71(1), 11-20. http://dx.doi.org/10.1111/1467-8624.00113

Liebenberg, L., Ungar, M., \& Van de Vijver, F. (2011). Validation of the child and youth resilience measure-28 (CYRM-28) among Canadian youth. Research on Social Work Practice, 22, 1-8. doi: 10.1177/104973511428619 
International Journal of Child, Youth and Family Studies (2014) 5(3): 423-446

Morse, J. M., Barrett, M., Mayan, M., Olson, K., \& Spiers, J. (2002). Verification strategies for establishing reliability and validity in qualitative research. International Journal of Qualitative Methods, 1(2), 1-19.

Mozaffarian, R. S., Wiecha, J. L., Roth, B. A., Nelson, T. F., Lee, R. M., \& Gortmaker, S. L. (2010). Impact of organizational intervention designed to improve snack and beverage quality in YMCA after-school programs. American Journal of Public Health, 100(5), 925-932. http://dx.doi.org/10.2105/ajph.2008.158907

National Center for Education Statistics. (2013). Number of students suspended and expelled from public elementary and secondary schools, by sex, race/ethnicity, and state: 2006. Retrieved from http://nces.ed.gov/programs/digest/d11/tables/dt11_170.asp

Nichols, J. D., \& Steffy, B. E. (1999). An evaluation of success in an alternative learning program: Motivational impact versus completion rate. Educational Review, 51(3), 207219. http://dx.doi.org/10.1080/00131919997452

Onwuegbuzie, A. J., \& Leech, N. L. (2006). Linking research questions to mixed methods data analysis procedures. The Qualitative Report, 11(3), 474-498. Retrieved from http://www.nova.edu/ssss/QR/QR11-3/onwuegbuzie.pdf

Pajares, F. (2005). Self-efficacy during childhood and adolescence: Implications for teachers and parents. In T. Urdan \& F. Pajares (Eds.), Self-efficacy beliefs of adolescents (pp. 339367). Charlotte, NC: Information Age Publishing.

Quane, J. M., \& Rankin, B. H. (2006). Does it pay to participate? Neighborhood-based organizations and the social development of urban adolescents. Children and Youth Services Review, 28(10), 1229-1250. http://dx.doi.org/10.1016/j.childyouth.2006.01.004

Raffaele Mendez, L. M. (2003). Predictors of suspension and negative school outcomes: A longitudinal investigation. New Directions for Youth Development, 99, 17-33. http://dx.doi.org/10.1002/yd.52

Skybo, T., \& Polivka, B. (2007). Heath promotion model for childhood violence prevention and exposure. Journal of Clinical Nursing, 16, 38-45. http://dx.doi.org/10.1111/j.1365-2702.2006.01621.x

St. Pierre, T. L., Mark, M. M., Kaltreider, D. L., \& Campbell, B. (2001). Boys and Girls Club and school collaborations: A longitudinal study of a multicomponent substance abuse prevention program for high-risk elementary school children. Journal of Community Psychology, 29, 87-106. http://dx.doi.org/10.1002/1520-6629(200103)29:2\%3C87:aid-jcop1007\%3E3.0.co;2-u

Tebes, J. K., Feinn, R., Vanderploeg, J. J., Chinman, M. J., Shepard, J., Branham, T., et al. (2007). Impact of a positive youth development program in urban after-school settings on the prevention of adolescent substance use. Journal of Adolescent Health, 41(3), 239247. http://dx.doi.org/10.1016/j.jadohealth.2007.02.016 
International Journal of Child, Youth and Family Studies (2014) 5(3): 423-446

Tobin, T., \& Sprague, J. (2000). Alternative education strategies: Reducing violence in school and the community. Journal of Emotional and Behavioral Disorders, 8(3), 177-186. http://dx.doi.org/10.1177/106342660000800305

Ungar, M., Brown, M., Liebenberg, L., Othman, R., Kwong, W. M., Armstrong, M., \& Gilgan, J. (2007). Unique pathways to resilience across cultures. Adolescence, 42(166), 287-310.

Ungar, M., \& Liebenberg, L. (2011). Assessing resilience across cultures using mixed methods: Construction of the Child and Youth Resilience Measure. Journal of Multiple Methods in Research, 5(2), 126-149. http://dx.doi.org/10.1177/1558689811400607

Ungar, M., Liebenberg, L., Boothroyd, R., Kwong, W. M., Lee, T. K., Leblanc, J., et al. (2008). The study of youth resilience across cultures: Lessons from a pilot study of measurement development. Research in Human Development, 5(3), 166-180. doi: 10.1080/15427600802274019

Vaughn, S., Schumm, J. S., \& Sinagub, J. (1996). Focus group interviews in education and psychology. Thousand Oaks, CA: Sage Publishing.

Weissman, M., Wolf, E., Sowards, K., Abaté, C., Weinberg, P., \& Marthia, C. (2005). School yard or prison yard: Improving outcomes for marginalized youth. Retrieved http://www.communityalternatives.org/pdf/sfs.pdf.

Whiteley, J. A., Napolitano, M. A., Lewis, B. A., Williams, D. M., Albrecht, A., Neighbors, C., et al. (2007). Commit to Quit in YMCAs: Translating an evidence-based quit smoking program for women into a community setting. Nicotine and Tobacco Research, 9(11), 1227-1235. http://dx.doi.org/10.1080/14622200701648334

Wong, N. A. (2010). “Cuz they care about the people who goes there”: The multiple roles of community-based youth center in providing “youth (comm) unity” for low-income Chinese American youth. Urban Education, 45(5), 708-739. doi: 10.1177/0042085909355766

Yampolskaya, S., Brown, E. C., \& Vargo, A. C. (2004). Assessment of teen pregnancy prevention interventions among middle school youth. Child and Adolescent Social Work Journal, 21(1), 69-83. http://dx.doi.org/10.1023/b:casw.0000012349.79750.b6 